\title{
Shelf-life and free radical scavenging activity of tomato (Lycopersicon esculentum Mill.) fruits coated with safe phytochemicals
}

\author{
Felix Managbanag Salas ${ }^{1, ~ *, ~ R o s a r i o ~ A l g o d o n ~ S a l a s ~}{ }^{2}$, Vivian Notarte Pole ${ }^{2}$, \\ Marcelo Amarila Quevedo ${ }^{3}$ \\ ${ }^{1}$ Dept of Pure \& Applied Chemistry, College of Arts \& Scences, Visayas State University, Baybay City, Leyte, Philippines \\ ${ }^{2}$ Dept of Horticulture, College of Agriculture \& Food Science, Visayas State University, Baybay City, Leyte, Philippines \\ ${ }^{3}$ PhilRootcrops, Visayas State University, Baybay City, Leyte, Philippines
}

\section{Email address:}

fmsalas_dopac@yahoo.com (F. M. Salas), rasalas_horti@yahoo.com (R. A. Salas), pole.vivian@yahoo.com (V. N. Pole), celoque777@yahoo.com (M. A. Quevedo)

\section{To cite this article:}

Felix Managbanag Salas, Rosario Algodon Salas, Vivian Notarte Pole, Marcelo Amarila Quevedo. Shelf-Life and Free Radical Scavenging Activity of Tomato (Lycopersicon Esculentum Mill.) Fruits Coated with Safe Phytochemicals. Journal of Food and Nutrition Sciences. Special Issue: Food Processing and Food Quality. Vol. 3, No. 1-2, 2015, pp. 94-99. doi: 10.11648/j.jfns.s.2015030102.28

\begin{abstract}
This study was conducted to investigate the potential of phytochemical extracts on extending the shelf-life of harvested tomato fruits, and to determine which phytochemical extracts can best enhance its shelf-life. The free radical scavenging activity (FRSA) of tomato fruits coated with phytochemical extracts stored under ambient condition and the toxicity of the phytochemical coatings was also evaluated. Mature green, breaker, and mature red tomato (Diamante max hybrid) fruits were used. The fruits were coated with phytochemical extracts derived from starfruit, cat's whisker, citronella, cocohusk, ginger, and hagimit. The extraction was accomplished using distilled water, ethyl alcohol, and acetic acid. The shelflife evaluation of the harvested tomato fruits was conducted in a completely randomized design at ambient condition. The results showed that the phytochemical extracts can potentially enhance the shelf-life of harvested tomatoes. The aqueous hagimit extract (AQHE) was able to extend the shelf-life of mature green tomatoes from 44 days to 97 days which is equivalent to $120 \%$ shelf-life enhancement. The ethanolic hagimit extract (ETHE) extended the shelf-life of breaker tomatoes from 27 days to 83 days which is about $207 \%$ shelf-life enhancement. The acetic acid starfruit extract (AASE) extended the shelf-life of mature red tomatoes from 17 days to 31 days which is tantamount to $82 \%$ enhancement of its shelf-life. These findings suggested the potential application of phytochemical extracts to solve the problem of high perishability of vegetables, particularly on tomatoes. The mature red tomatoes gave the highest FRSA among the three maturity stages of tomato tested. However, the FRSA of mature green and breaker tomatoes increased with shelf-life extension. The sustenance of FRSA on coated mature red tomato with extended shelf-life is noteworthy to consider. Furthermore, the acute toxicity tests revealed that these phytochemical coatings are non-toxic and are safe to use as coatings on agricultural products for human consumption.
\end{abstract}

Keywords: Cat's Whisker Extract, Free Radical Scavenging Activity, Hagimit Extract, Phytochemical Extract, Tomato, Starfruit Extract, Toxicity

\section{Introduction}

\subsection{Nature and Importance of the Study}

Vegetables are short duration crops which are easily adjusted in crop diversification (Bautista \& Esguerra, 2007), provide higher yield and return to resource-poor farmers. In the Philippines, vegetables contribute $8 \%$ of the total agricultural input while utilizing only $5 \%$ of the agricultural area. This means that more income can be derived from vegetables per unit area and time compared to other crops like cereals and plantation crops. The vegetable industry has shown growth by $13.3 \%$ in the last seven years which is about $2 \%$ per year. The total exports derived from vegetables reached about $31 \mathrm{M}$ USD which include tomato among others. However, the aggregate domestic demand for vegetables in the region is greater than the reported consumption. In Leyte province alone, the deficit was more 
than 37 metric tons in 1997-1998 (BAS, 1998). The problems of the local and national vegetable industry relate to production, postproduction, marketing and infrastructure. Often cited under postproduction problem is the lack of information to manage the high perishability of harvested vegetables (AARNET, 2006) that would affect their marketability, which when not properly taken cared of may result to losses of income to farmers.

A widely grown vegetable in the world, tomato is one of the most important vegetables in Asia and in the Philippines. It is rich in nutrients such as vitamins, minerals, and antioxidants (Marxen et al., 2007; Srinivasan, 2010). It is also considered an important dietary component because it contains high levels of lycopene, an antioxidant that reduces the risks associated with cancers and neurodegenerative diseases (Miller et al., 2002).

Preliminary studies conducted at the Department of Pure and Applied Chemistry of the Visayas State University, Philippines have shown some potentials of phytochemical extracts to enhance the shelf-life of highly perishable vegetables. Some plant extracts and natural products have been reported potential commodity coatings that can promote safety, profitability and quality of harvested vegetables. The human body must be protected from the onset of degenerative diseases as well as from toxicants that are often used to handle and preserve vegetable harvests. The recommended vegetable consumption is $200 \mathrm{~g} /$ capita/day (AARNET, 2006). However, with the massive use of persistent pesticides against obnoxious plants, pest and diseases, these health benefits are less felt than the alarming effect of harmful pesticides and toxicants. Vegetable farms should always consider food safety and environment friendly production and postproduction systems. Thus, this study on safe phytochemical coatings to enhance the shelf-life of tomato fruits was conducted.

\subsection{Objectives of the Study}

This study was conducted to:

1. Investigate the potential of phytochemical extracts on extending the shelf-life of harvested tomato fruits;

2. Determine which of the phytochemical extracts can best enhance the shelf-life of tomato under ambient condition;

3. Evaluate the free radical scavenging activity of tomato fruits coated with phytochemical extracts stored under ambient condition; and

4. Assess the toxicity of the phytochemical coatings that enhanced the shelf-life of harvested tomato fruits.

\section{Materials and Methods}

\subsection{Collection and Preparation of Phytochemical Extracts}

Leaves of starfruit (Averrhoa carambola L.), cat's whisker (Orthosiphon aristatus (Blume) Miq.), citronella (Cymbopogon nardus L.), fruit of hagimit (Ficus minahasse Miq.), husk of young green coconut (Cocos nucefera L.) and rhizomes of turmeric (Curcuma longa L.) were collected around the vicinity of the Visayas State University. They were washed with tap water to remove adhering foreign matters. The leaves and rhizomes were cut, sliced into small pieces, and percolated separately with distilled water, ethanol, and acetic acid as extractants. Every gram of the plant material was added wth 10 milliliter of the solvent and the mixtures were percolated overnight or for 12 hours. The mixtures were then filtered using Whatman \#42 filter paper and the corresponding filtrates were diluted to $1 \%$ concentration as coating solutions for the tomato fruits. Meanwhile, the collected hagimit fruits were first air-dried and grounded prior to solvent extraction following the same procedure as in other plant materials.

\subsection{Coating of Harvested Tomato Fruits}

Three maturity stages of Diamante max tomatoes were used in the experiment: mature green, breaker, and mature red. In the first experiment, coating was done by dipping the mature red tomato fruits with the aqueous phytochemical extracts for five minutes. After the first experiment, three potential sources of phytochemicals were selected. In the second experiment, the aqueous, ethanolic and acetic acid extracts of the selected sources of phytochemicals were used as coating solutions on mature green, breaker, and mature red tomato fruits.

\subsection{Shelf-Life Evaluation of Harvested Tomato}

The coated fruits of tomato were placed on plastic trays in triplicates arranged in a completely randomized design and stored at the vegetable research laboratory of the Department of Horticulture of the Visayas State University at ambient condition. The visual quality ratings (VQR) and weight loss (Acedo, 1999) were recorded daily. A replicate or a treatment is terminated once the vegetable fruits attained a VQR of 3 or a $50 \%$ weight loss. The treatments of the final shelf-life evaluation were as follows: $\mathrm{T} 0=$ untreated, $\mathrm{T} 1=$ distilled water, T2 $=$ ethanol, T3 $=$ acetic acid, T4 $=$ alum solution, T5 $=$ aqueous starfruit extract (AQSE), T6 = ethanolic starfruit extract (ETSE), T7 = acetic acid starfruit extract (AASE), T8 $=$ aqueous cat's whisker extract (AQCWE), T9 = ethanolic cat's whisker extract (ETCWE), T9 = acetic acid cat's whisker extract $(\mathrm{AACWE}), \mathrm{T} 11=$ aqueous hagimit extract (AQHE), T12 = ethanolic hagimit extract (ETHE), and T13 = acetic acid hagimit extract (AAHE). Analysis of variance (ANOVA) was used to determine the significance of results and the differences were assessed using Tukey's Honesty Significant Difference (HSD) at $5 \%$ probability.

\subsection{Free Radical Scavenging Activity (FRSA) of Harvested Tomato}

Representative samples of the tomato fruit vegetables were selected before the coating process. These were subjected to free radical scavenging assay using 1,1-diphenyl-2picrylhydrazyl (DPPH) method by Hatano et al. (1998). Trolox was used as the reference standard to establish the FRSA of the fruit vegetables. As soon as the shelf-life evaluation is terminated for a particular replicate, a 
representative sample of the fruit was again analyzed for free radical scavenging activity. This analysis was accomplished using an ultraviolet-visible spectrophotometer set at $517 \mathrm{~nm}$ wavelength. The calculation of FRSA ( $\mu$ molTE/100g) was based on the established calibration curve between the reaction of DPPH and Trolox which was done prior to the analysis of the selected tomato fruit samples.

\subsection{Toxicity Evaluation of Bioactive Phytochemical Extracts}

The effective shelf-life enhancer of tomato fruits were subjected to acute toxicity test using albino mice as the test organisms. Six- to eight-week old, active, good-looking and healthy experimental animals were used in the toxicity evaluation. Twenty mice were used per treatment composed of 10 females and 10 males. They were acclimatized for a week before they were fed with the phytochemical coatings that showed positive result on the shelf-life evaluation of tomato fruits. The mice received a dosage of 15,000 mg per kilogram body weight and observations were done for a week. All the mice were fed ad libitum using commercial feeds with drinking water constantly supplied for the test animals.
Mortality or death and occurrence of illness or weakness were observed and recorded throughout the observation period. Dead experimental animals were submitted for hispathological examinations at the College of Veterinary Medicine of the Visayas State University, Visca, Baybay City, Leyte, Philippines.

\section{Results and Discussion}

Table 1 shows the average shelf-life (days) of mature red tomatoes coated with aqueous phytochemical extracts. The untreated tomato fruits exhibited an average shelf-life of 13 days. The aqueous starfruit (AQSE), cat's whisker (AQCWE), and hagimit (AQHE) extracts extended the shelf-life of mature red tomato fruits up to $29.7,19.3$, and 30.3 days, respectively. The shelf-life of those fruits coated with citronella, cocohusk, and turmeric extracts was not enhanced; rather the shelf-life was even shortened. These results indicate the presence of bioactive components in starfruit, cat's whisker, and hagimit plants. This is the basis of considering starfruit, cat's whisker, and hagimit as sources of phytochemicals that can possibly promote shelf-life of tomatoes.

Table 1. Shelf-life (days) evaluation of mature red tomato fruits coated with aqueous phytochemicals

\begin{tabular}{ccccc}
\hline \multirow{2}{*}{ Treatments } & & & Shelf-life (Days) & \\
\cline { 2 - 5 } & R1 & R2 & R3 & Average \\
\hline T0 & 14 & 12 & 13 & 14 \\
T1 & 12 & 13 & 30 & $13.0^{\mathrm{c}}$ \\
T2 & 27 & 32 & 20 & $2.0^{\mathrm{c}}$ \\
T3 & 19 & 20 & 13 & $19.7^{\mathrm{b}}$ \\
T4 & 12 & 12 & 12 & $12.3^{\mathrm{c}}$ \\
T5 & 12 & 12 & 30 & $12.0^{\mathrm{c}}$ \\
T6 & 31 & 30 & 13 & $30.3^{\mathrm{a}}$ \\
T7 & 12 & 13 & $13.7^{\mathrm{c}}$ \\
\hline
\end{tabular}

Means having the same letter(s) within a column are not significant from each other based on 0.05 HSD.

$\mathrm{T} 0=$ Untreated $\quad \mathrm{T} 1=$ Distilled water $\quad \mathrm{T} 2=$ Starfruit extract $\quad \mathrm{T} 3=$ Cat's whisker extract $\quad \mathrm{T} 4=$ Citronella extract $\quad \mathrm{T} 5=$ Coco husk extract $\mathrm{T} 6=$ Hagimit extract $\quad \mathrm{T} 7=$ Turmeric extract

Table 2. Average weight loss (\%) of tomato fruits coated with phytochemicals under ambient condition

\begin{tabular}{|c|c|c|c|}
\hline \multirow{2}{*}{ Treatments } & \multicolumn{3}{|c|}{ Weight loss (\%) } \\
\hline & Mature green & Breaker & Mature Red \\
\hline T0 & $48.6^{\mathrm{a}}$ & $54.0^{\mathrm{a}}$ & $54.9^{\mathrm{a}}$ \\
\hline $\mathrm{T} 1$ & $54.8^{\mathrm{a}}$ & $50.1^{\mathrm{a}}$ & $59.8^{\mathrm{a}}$ \\
\hline $\mathrm{T} 2$ & $53.2^{\mathrm{a}}$ & $55.4^{\mathrm{a}}$ & $55.6^{\mathrm{a}}$ \\
\hline $\mathrm{T} 3$ & $55.6^{\mathrm{a}}$ & $51.6^{\mathrm{a}}$ & $44.8^{\mathrm{ab}}$ \\
\hline $\mathrm{T} 4$ & $55.1^{\mathrm{a}}$ & $53.8^{\mathrm{a}}$ & $17.1^{\mathrm{c}}$ \\
\hline T5 & $36.1^{\mathrm{b}}$ & $31.2^{\mathrm{b}}$ & $49.6^{\mathrm{a}}$ \\
\hline T6 & $31.1^{\mathrm{b}}$ & $35.0^{\mathrm{b}}$ & $43.4^{\mathrm{b}}$ \\
\hline $\mathrm{T} 7$ & $29.3^{\mathrm{b}}$ & $31.0^{\mathrm{b}}$ & $42.2^{\mathrm{b}}$ \\
\hline $\mathrm{T} 8$ & $51.2^{\mathrm{a}}$ & $57.9^{\mathrm{a}}$ & $54.1^{\mathrm{a}}$ \\
\hline T9 & $54.4^{\mathrm{a}}$ & $12.6^{\mathrm{c}}$ & $17.5^{\mathrm{c}}$ \\
\hline $\mathrm{T} 10$ & $50.3^{\mathrm{a}}$ & $12.7^{\mathrm{c}}$ & $17.3^{\mathrm{c}}$ \\
\hline T11 & $20.7^{\mathrm{c}}$ & $12.7^{\mathrm{c}}$ & $13.7^{\mathrm{c}}$ \\
\hline $\mathrm{T} 12$ & $21.5^{\mathrm{c}}$ & $28.2^{\mathrm{b}}$ & $17.1^{\mathrm{c}}$ \\
\hline $\mathrm{T} 13$ & $25.3^{\mathrm{c}}$ & $24.6^{\mathrm{bc}}$ & $17.2^{\mathrm{c}}$ \\
\hline
\end{tabular}

Means having the same letter(s) within a column are not significant from each other based on 0.05 HSD.

$\mathrm{T} 0=$ Untreated $\quad \mathrm{T} 1=$ Distilled water $\quad \mathrm{T} 2=$ Ethanol $\quad \mathrm{T} 3=$ Acetic acid $\quad \mathrm{T} 4=$ Alum solution $\quad \mathrm{T} 5=$ Aqueous starfruit extract $(\mathrm{AQSE}) \quad \mathrm{T} 6=\mathrm{Ethanolic}$ starfruit extract (ETSE) $\quad$ T7 = Acetic acid starfruit extract (AASE) $\quad$ T8 = Aqueous cat's whisker extract (AQCWE) T9= Ethanolic cat's whisker extract $($ ETCWE $) \quad$ T10 = Acetic acid cat's whisker extract $($ AACWE $) \quad$ T11 $=$ Aqueous hagimit extract $(\mathrm{AQHE}) \quad \mathrm{T} 12=$ Ethanolic hagimit extract $(\mathrm{ETHE})$ T13 = Acetic acid hagimit extract (AAHE) 
Table 3. Average shelf-life (days) of tomato fruits coated with phytochemicals under ambient condition

\begin{tabular}{|c|c|c|c|}
\hline \multirow{2}{*}{ Treatments } & \multicolumn{3}{|c|}{ Shelf-life (Days) } \\
\hline & Mature green & Breaker & Mature Red \\
\hline T0 & $43.7^{\mathrm{d}}$ & $26.7^{\mathrm{e}}$ & $17.0^{\mathrm{d}}$ \\
\hline $\mathrm{T} 1$ & $44.0^{\mathrm{d}}$ & $23.0^{\mathrm{e}}$ & $17.7^{\mathrm{d}}$ \\
\hline $\mathrm{T} 2$ & $45.7^{\mathrm{d}}$ & $32.0^{\mathrm{d}}$ & $18.7^{\mathrm{c}}$ \\
\hline T3 & $15.0^{\mathrm{f}}$ & $15.0^{f}$ & $13.0^{\mathrm{e}}$ \\
\hline $\mathrm{T} 4$ & $34.0^{\mathrm{e}}$ & $27.0^{\mathrm{e}}$ & $20.0^{\mathrm{c}}$ \\
\hline $\mathrm{T} 5$ & $72.3^{\mathrm{c}}$ & $62.7^{\mathrm{b}}$ & $30.3^{\mathrm{a}}$ \\
\hline $\mathrm{T} 6$ & $72.7^{\mathrm{c}}$ & $60.3^{\mathrm{b}}$ & $30.3^{\mathrm{a}}$ \\
\hline $\mathrm{T} 7$ & $76.3^{\mathrm{bc}}$ & $64.3^{\mathrm{b}}$ & $30.7^{\mathrm{a}}$ \\
\hline $\mathrm{T} 8$ & $58.7^{\text {cd }}$ & $26.0^{\mathrm{e}}$ & $19.3^{\mathrm{c}}$ \\
\hline T9 & $36.0^{\mathrm{e}}$ & $30.0^{\mathrm{d}}$ & $27.0^{\mathrm{b}}$ \\
\hline $\mathrm{T} 10$ & $46.0^{\mathrm{d}}$ & $37.0^{\mathrm{d}}$ & $30.0^{\mathrm{a}}$ \\
\hline $\mathrm{T} 11$ & $97.3^{\mathrm{a}}$ & $34.3^{\mathrm{d}}$ & $19.3^{\mathrm{c}}$ \\
\hline $\mathrm{T} 12$ & $93.0^{\mathrm{a}}$ & $83.0^{\mathrm{a}}$ & $20.0^{c}$ \\
\hline $\mathrm{T} 13$ & $85.0^{\mathrm{b}}$ & $49.0^{\mathrm{c}}$ & $30.0^{\mathrm{a}}$ \\
\hline
\end{tabular}

Means having the same letter(s) within a column are not significant from each other based on 0.05 HSD.

$\mathrm{T} 0=$ Untreated $\quad \mathrm{T} 1=$ Distilled water $\quad \mathrm{T} 2=$ Ethanol $\quad \mathrm{T} 3=$ Acetic acid $\quad \mathrm{T} 4=$ Alum solution

T9 = Ethanolic cat's whisker extract (ETCWE) $\quad$ T10 = Acetic acid cat's whisker extract (AACWE)

$\mathrm{T} 12=$ Ethanolic hagimit extract $(\mathrm{ETHE}) \quad \mathrm{T} 13=$ Acetic acid hagimit extract $(\mathrm{AAHE})$

T5 = Aqueous starfruit extract (AQSE)

$\mathrm{T} 8=$ Aqueous cat's whisker extract (AQCWE)

T11 = Aqueous hagimit extract $(\mathrm{AQHE})$

Table 4. Free Radical Scavenging Activity ( $\mu$ molTE/100g) of Tomato (Lycopersicon esculentum Mill.) Fruits Coated with Safe Phytochemicals

\begin{tabular}{|c|c|c|c|c|c|c|}
\hline \multirow{3}{*}{ Treatments } & \multicolumn{6}{|c|}{ Free Radical Scavenging Activity ( molTE/100g) } \\
\hline & \multicolumn{2}{|c|}{ Mature Green } & \multicolumn{2}{|c|}{ Breaker } & \multicolumn{2}{|c|}{ Mature Red } \\
\hline & Fresh & Stored & Fresh & Stored & Fresh & Stored \\
\hline Untreated & 114.1 & $265.7^{\mathrm{b}}$ & 189.1 & $267.8^{\text {bcde }}$ & 270.6 & $272.6^{\mathrm{ab}}$ \\
\hline Distilled water & 114.1 & $250.2^{\text {bcde }}$ & 189.1 & $294.7^{\mathrm{abc}}$ & 270.6 & $277.1^{\mathrm{a}}$ \\
\hline Ethanol & 114.1 & $240.9^{\text {cdef }}$ & 189.1 & $202.3^{\mathrm{f}}$ & 270.6 & $240.1^{\mathrm{abc}}$ \\
\hline Acetic acid & 114.1 & $229.1^{\mathrm{efgh}}$ & 189.1 & $270.6^{\text {bcd }}$ & 270.6 & $263.9^{\mathrm{ab}}$ \\
\hline Alum solution & 114.1 & $216.3^{\mathrm{gh}}$ & 189.1 & $216.4^{\mathrm{def}}$ & 270.6 & $266.9^{\mathrm{ab}}$ \\
\hline ETSE & 114.1 & $262.7^{\mathrm{bc}}$ & 189.1 & $262.1^{\text {bcde }}$ & 270.6 & $286.4^{\mathrm{a}}$ \\
\hline AASE & 114.1 & $256.7^{\text {bcd }}$ & 189.1 & $300.2^{\mathrm{ab}}$ & 270.6 & $277.5^{\mathrm{ab}}$ \\
\hline AQCWE & 114.1 & $207.6^{\mathrm{hi}}$ & 189.1 & $213.4^{\mathrm{def}}$ & 270.6 & $211.1^{b c}$ \\
\hline ETCWE & 114.1 & $211.1^{\text {ghi }}$ & 189.1 & $218.4^{\text {def }}$ & 270.6 & $191.7^{\mathrm{c}}$ \\
\hline AACWE & 114.1 & $189.3^{\mathrm{i}}$ & 189.1 & $209.6^{\mathrm{ef}}$ & 270.6 & $195.4^{\mathrm{c}}$ \\
\hline AQHE & 114.1 & $338.5^{\mathrm{a}}$ & 189.1 & $334.7^{\mathrm{a}}$ & 270.6 & $269.5^{\mathrm{ab}}$ \\
\hline ETHE & 114.1 & $340.9^{a}$ & 189.1 & $337.5^{\mathrm{a}}$ & 270.6 & $273.7^{\mathrm{ab}}$ \\
\hline
\end{tabular}

Means having the same letter(s) within a column are not significant from each other based on 0.05 HSD.

AQSE $=$ aqueous starfruit extract $\quad$ AQCWE $=$ aqueous cat's whisker extract $\quad$ AQHE $=$ aqueous hagimit extract $\quad$ ETSE $=$ ethanolic starfruit extract

ETCWE $=$ ethanolic cat's whisker extract $\quad$ ETHE $=$ ethanolic hagimit extract $\quad$ AASE $=$ acetic acid starfruit extract AACWE $=$ acetic acid cat's whisker

extract $\quad \mathrm{AAHE}=$ acetic acid hagimit extract

Table 5. Toxicity evaluation of phytochemicals at a dosage of $15 \mathrm{~g} / \mathrm{kg}$ body weight on albino mice

\begin{tabular}{|c|c|c|c|c|c|c|c|}
\hline \multirow{2}{*}{ Treatments } & \multirow{2}{*}{$\begin{array}{c}\text { Number of female } \\
\text { mice }\end{array}$} & \multirow{2}{*}{$\begin{array}{c}\text { Number of male } \\
\text { mice }\end{array}$} & \multicolumn{5}{|c|}{ Mortality } \\
\hline & & & $48 \mathrm{hrs}$ & 96 hrs & 144 hrs & 182 hrs & 240 hrs \\
\hline Control (Untreated) & 10 & 10 & 0 & 0 & 0 & 0 & 0 \\
\hline Distilled water & 10 & 10 & 0 & 0 & 0 & 0 & 0 \\
\hline Ethanol & 10 & 10 & 0 & 0 & 0 & 0 & 0 \\
\hline Acetic acid & 10 & 10 & 0 & 0 & 0 & 0 & 0 \\
\hline AQBE & 10 & 10 & 0 & 0 & 0 & 0 & 0 \\
\hline AQHE & 10 & 10 & 0 & 0 & 0 & 0 & 0 \\
\hline ETBE & 10 & 10 & 0 & 0 & 0 & 0 & 0 \\
\hline ETHE & 10 & 10 & 0 & 0 & 0 & 0 & 0 \\
\hline $\mathrm{AABE}$ & 10 & 10 & 0 & 0 & 0 & 0 & 0 \\
\hline AACWE & 10 & 10 & 0 & 0 & 0 & 0 & 0 \\
\hline AAHE & 10 & 10 & 0 & 0 & 0 & 0 & 0 \\
\hline
\end{tabular}

Means with the same letter(s) within a column are not significant from each other based on 0.05 HSD.

$\mathrm{AQSE}=$ Aqueous starfruit extract $\quad \mathrm{AQHE}=$ Aqueous hagimit extract $\quad$ ETSE $=$ Ethanolic starfruit extract

AASE $=$ Acetic acid starfruit extract

$\mathrm{AACWE}=$ Acetic acid cat's whisker extract

$\mathrm{ETHE}=$ Ethanolic hagimit extract AAHE $=$ Acetic acid hagimit extract 
Table 2 shows the average weight loss (\%) of tomato fruits coated with phytochemical extracts. Coated tomatoes generally exhibited lower weight loss compared to the control. The fruits applied with hagimit extracts showed the lowest weight loss. In fact, this observation has been consistently observed on the mature green, breaker, and mature red fruits of tomato. This may indicate some influence of the hagimit extracts on the respiration of tomato fruits. The degradation of tomato fruits is highly associated with its respiration (Odo and Salas, 2014).

Table 3 shows the average shelf-life (days) of tomato fruits coated with phytochemical extracts. The aqueous hagimit extract (AQHE) was able to enhance the shelf-life of mature green tomato fruits from 44 days of what has been observed in the control to 97 days but only a very slight enhancement on breaker and mature red tomato fruits. The ethanolic hagimit (ETHE) and acetic acid starfruit (AASE) extracts best enhanced the shelf-life of breaker tomato from 27 days to 83 days and from 17 days to 31 days on mature red tomato fruits, respectively. These shelf-life data significantly exceeded that of the report published by Yaptenco et al. (2007). This finding also illustrates the presence of chemical components such as flavonoids, saponins, and tannins (Jacob et al., 2010) in these plants that can promote the shelf-life of tomato fruits.

Table 4 shows the average free radical scavenging activity ( $\mu$ molTE/100g) of tomato fruits coated with phytochemical extracts. Freshly harvested mature red tomato fruits showed the highest free radical scavenging activity compared to the mature green and breaker fruits. This can be explained by the developments of antioxidant components in mature red fruits. Tomatoes have been known for its lycopene and the result may also indicate higher lycopene content on mature red tomato fruits. Additionally, mature green and breaker tomato fruits coated with aqueous (AQHE) and ethanolic hagimit (ETHE) extracts gave the highest FRSA which was even increased with shelf-life extension. However, mature red tomato fruits coated with starfruit extract manifested the highest FRSA although its value was not statistically different from those fruits coated with Hagimit extracts. In other words, tomato fruits coated with starfruit and hagimit extracts showed better free radical scavenging activity upon storage under ambient condition. A sustained free radical scavenging activity was indeed observed on tomato fruits with extended and prolonged shelf-life. This means that the antioxidant value of stored tomato fruits is maintained and is not altered but preserved with starfruit and hagimit phytochemical coatings.

Table 5 shows the toxicity evaluation of the phytochemical extracts that exhibited shelf-life enhancement on tomato fruits. The acute toxicity test was done by oral administration of the extracts into the digestive system of the test animals. Six- to eight-week old albino mice were used in the toxicity evaluation and received a dosage of 15,000 milligram of the coating solution per kilogram body weight of the experimental animals. Ten males and ten females were used in the experiment after a week of acclimatization. No mortality was noted in all the treatments even after a week of observation. This only indicates that the phytochemicals used as coatings to enhance the shelf-life of harvested tomato fruits are non-toxic and are safe for food commodities.

The result of the study only indicates the usefulness of phytochemical coatings not only on shelf-life enhancement, but also on improving the antioxidant property of stored vegetable tomato fruit. The overall result gave us a picture that can paint several advantages and benefits that can be derived from safe phytochemical coatings.

\section{Conclusions}

From the result of the study, the following conclusions were drawn:

1. Phytochemical extracts derived from hagimit and starfruit are potential shelf-life enhancer of harvested tomato fruits;

2. Aqueous hagimit extract (AQHE) extended the shelflife of mature green tomato fruits from 44 to 97 days; ethanolic hagimit extract (ETHE) extended the shelflife of breaker tomato fruits from 27 to 83 days; acetic acid starfruit extract (AASE) extended the shelf-life of mature red tomato fruits from 17 to 31 days;

3. The free radical scavenging activity of mature green and breaker tomatoes increased with the shelf-life extension of the stored fruits, but a sustained FRSA was observed on coated mature red tomatoes; and

4. The phytochemical coatings derived from cat's whisker, hagimit and starfruit are non-toxic and are safe for food products.

\section{Recommendations}

The following recommendations are hereby suggested for future directions:

1. Application of these phytochemical extracts to other fruit vegetables under different storage conditions;

2. Elucidation of the bioactive phytochemical principles; and

3. Product development for commercialization.

\section{Acknowledgments}

The authors are thankful to the Philippine Council for Agriculture, Aquatic and Natural Resources Research and Development (PCAARRD) and the Visayas State University (VSU) for the financial support given to this research project as well as the travel grant extended by the Commission on Higher Education (CHED) of the Philippines. 


\section{References}

[1] AARNET. 2006. AVRDC - The World Vegetable Center web publication

[2] Acedo, A.L. Jr. 1999. Postharvest physiology of perishable crops. Laboratory Manual in Horticulture 111. Department of Horticulture, College of Agriculture, Visayas State University, Visca, Baybay, Leyte, Philippines

[3] Apel, K. and Hirt, H. 2004. Reactive oxygen species: metabolism, oxidative stress and signal transduction. Аnnu. Rev. Plant Biol., 55:373-399

[4] BAS. 1998. Bureau of Agricultural Statistics Report.

[5] Bautista, O.K. and Esguerra, E.B. (eds). 2007. Postharvest technology for Southeast Asian perishable crops. Second Edition. UPLB, College, Laguna

[6] Fang, Y.Z., Yang, S. and Wu, G. 2002. Free radicals, antioxidants, and nutrition. Nutrition, 18:872-879.

[7] Hatano, T., Kagawa, H., Yasuhara, T. and Okuda, T. 1998. Two new flavonoids and their constituents in licorice root: their relative astringency and radical scavenging effects. Chemical and Pharmaceutical Bulletin, 36:2090-2097.

[8] Jacob, K., Garcia-Alonso, F.J. and G. Ros. 2010. Stability of carotenoids, phenolic compounds, ascorbic acid and antioxidant capacity of tomatoes during thermal processing. Arch Latinoam Nutr., 60(2):192-198.

[9] Marxen, K., Vanselow, K.H., Lippemeier, S., Hintze, R., Ruser, A. and Hansen, U. 2007. Determination of DPPH Radical Oxidation Caused by Methanolic Extracts of Some Microalgal Species by Linear Regression Analysis of Spectrometric Measurements. Sensors, 7:2080-2095.

[10] Miller, E.C., Hadley, C.W., Schwartz, S.J., Erdman, J.W., Boileau, T.M.W. and Clinton, S.K. 2002. Lycopene, tomato products, and prostate cancer prevention. Have we established causality? Pure Appl. Chem., 74(8):1435-1441.

[11] Odo, A. and Salas, F.M. 2014. Respired Carbon Dioxide Analysis of Harvested Tomato (Lycopersicon esculentum Mill.) Fruits Coated with Polar Hagimit (Ficus minahassae Miq.) Extracts. In Proceedings: $44^{\text {th }}$ CSSP Scientific Conference held in Parklane International Hotel, Cebu City, Philippines on May 12-16, 2014.

[12] Srinivasan, R. 2010. Safer Tomato Production Methods: A field guide for soil fertility and pest management. AVRDCThe World Vegetable Center, Shanhua, Taiwan. AVRDC Publication No. 10-740. 97p.

[13] Yaptenco, K.F., Amatorio, E.Q. and Bautista, O.K. 2007. Refrigerated Transport and Storage. In Postharvest Technology for Southeast Asian Perishable Crops. Second Edition. Bureau of Agricultural Research -Department of Agriculture, Diliman, Quezon City. 